\title{
Synthesis and density-functional-theory calculations of electronic band structure of hollow sphere $\mathbf{W S}_{2}$
}

\author{
Maxwell Selase Akple*, Holali Kwami Apevienyeku
}

Mechanical Engineering Department, Ho Technical University, P.O. Box HP 217, Ho, Volta Region, Ghana

\begin{abstract}
A novel and low-cost synthesis of tungsten disulfide $\left(\mathrm{WS}_{2}\right)$ transition metal dichalcogenide was carried out via gas-solid reaction in a horizontal quartz reactor. In this process, the prepared hollow $\mathrm{WO}_{3}$ precursor was sulfided with $\mathrm{CS}_{2}$ at $550{ }^{\circ} \mathrm{C}$ at different durations under $\mathrm{N}_{2}$ gas atmosphere. The as-prepared $\mathrm{WS}_{2}$ samples were formed by substitution of $\mathrm{O}$ by $\mathrm{S}$ during the sulfidation process. The characterization of these samples was performed employing X-ray diffraction (XRD), scanning electron microscopy (SEM), transmission electron microscopy (TEM), energy dispersive X-ray (EDX), Brunauer-Emmett-Teller (BET) specific surface area, X-ray photoelectron spectroscopy (XPS) and UV-Vis absorption spectroscopy. The characterization results showed that the as-prepared $\mathrm{WS}_{2}$ samples were of high quality and purity. No significant differences were observed in various $\mathrm{WS}_{2}$ samples synthesized during different sulfidation periods. The calculated results obtained from the density functional theory (DFT) indicate that $\mathrm{WS}_{2}$ has an indirect band gap of ca. $1.56 \mathrm{eV}$, which is in agreement with experimental band gap of ca. $1.50 \mathrm{eV}$. Combining the experimental and DFT results suggests that the novel method used in the synthesis of $\mathrm{WS}_{2}$ has a potential application for large scale production. The obtained $\mathrm{WS}_{2}$ are of high quality and can be implemented in photocatalysis, catalysis, photovoltaics, optoelectronic devices and photosensor devices.
\end{abstract}

Keywords: transition metal dichalcogenide; $\mathrm{WS}_{2} ; \mathrm{DFT}$

\section{Introduction}

Transition metal dichalcogenides (TMDCs) are the group of layered nanomaterials which have attracted a lot of interest in recent times. TMDCs are group IV-VII metals with the chemical structure like $\mathrm{MX}_{2}$, where $\mathrm{M}$ is a transition metal atom (e.g. tungsten, molybdenum) and $\mathrm{X}$ is a chalcogen atom (e.g. S, Se, Te, etc.) [1, 2]. The $\mathrm{X}-\mathrm{M}-\mathrm{X}$ slab structure is built of two layers of carefully packed chalcogenide atoms sandwiching one metal layer between them. The slabs are stacked with only van der Waals forces. They exhibit semiconducting, metallic and even superconducting behavior, hence, have a broad range of applications in nanoelectronics and optoelectronics [3-9]. The semiconducting phases of TMDCs, such as $\mathrm{MoS}_{2}$, $\mathrm{WS}_{2}, \mathrm{WSe}_{2}, \mathrm{MoSe}_{2}$ in the bulk form, have an indirect band gap [10, 11]. However, modification of the bulk properties into a mono- or few-layered structure could significantly change them into direct band gap [3]. These variations in the band

*E-mail: makple@htu.edu.gh structure show potential application of the TMDCs in new structures development. These properties have drawn the attention of many scientists who are progressively studying the modifications of the TMDCs. According to the studies, many synthetic methods have been reported for the preparation of TMDCs including solid-gas or gasphase reactions, electron beam irradiation activation and arc discharge, thermal decomposition, spray pyrolysis, hydrothermal or solvothermal synthesis, sono-electrochemical process and template synthesis [12-19].

Tungstenite or tungsten disulfide $\left(\mathrm{WS}_{2}\right)$ semiconductor material belongs to the TMDCs which have drawn the attention of researchers. In the bulk form, it has a band gap of $\sim 1.3 \mathrm{eV}$, which is inactive because its redox potentials of photogenerated electrons and holes are not sufficient for the interfacial charge transfer onto adsorbed molecules for many photocatalytic applications [20]. However, this band gap can be tuned to more suitable values through quantum confinement effects for practical applications in photovoltaics and photocatalysis $[11,21]$. Different approaches have been 
suggested for the preparation and tuning of the crystal structure and the number of layers of $\mathrm{WS}_{2}$. They included mechanical exfoliation, chemical vapor deposition (CVD), liquid exfoliation and sulfurization of transition metal and metal oxide [8, 22-26]. The $\mathrm{WS}_{2}$ produced by these methods are slightly different in structure depending on the precursor(s) used and the rate of $\mathrm{WS}_{2}$ formation [26]. Besides, some of these methods also use toxic and hazardous gasses such as $\mathrm{H}_{2} \mathrm{~S}$ which are difficult to handle and require high-temperature procedures which may result in cost increase and further limit the potential applications [17, 27]. Sun et al. [28] showed that for industrial production of $\mathrm{WS}_{2}$, the most successful technique is the conversion of oxide-to-sulfide.

To obtain high-quality $\mathrm{WS}_{2}$, the morphology of the oxide precursor is crucial. Hence, high-quality precursors which show unique plane structural defects are essential for the preparation of $\mathrm{WS}_{2}$ with ordered and stacked layered structure. Herein, we report the synthesis of the hollow sphere $\mathrm{WS}_{2}$ layered structure using a prepared solid $\mathrm{WO}_{3}$ hollow sphere as a precursor. The synthesis method is simple, convenient and efficient, where the $\mathrm{WO}_{3}$ hollow microsphere used as a precursor is placed in a horizontal tubular quartz reactor, and $\mathrm{CS}_{2}$ vapor is passed through the system. The substitution of $\mathrm{O}$ by $\mathrm{S}$ along the $\left(\begin{array}{lll}0 & 0 & 1\end{array}\right)$ planes of $\mathrm{WO}_{3}$ converts the $\mathrm{WO}_{3}$ precursor to $\left(\begin{array}{lll}0 & 0 & 2\end{array}\right) \mathrm{WS}_{2}$ planes. This preparation technique has a potential for large scale production of $\mathrm{WS}_{2}$ because of its simplicity, inexpensiveness, easy to control, and environmental friendliness. Further investigation into the electronic structure of bulk $\mathrm{WS}_{2}$ was carried out from first-principles calculations using density functional theory (DFT). The acquired knowledge would provide an insight into the values which would enable practical synthesis and application of $\mathrm{WS}_{2}$.

\section{Experimental}

\subsection{Preparation of $\mathrm{WO}_{3}$ hollow sphere}

All chemicals were of analytical grade and used without further purification. The detailed experimental process for the preparation of $\mathrm{WO}_{3}$ has been reported in previous studies $[29,30]$. Three starting aqueous solutions, $\mathrm{SrCl}_{2}(0.1 \mathrm{~mol} / \mathrm{L}), \mathrm{Na}_{2} \mathrm{WO}_{4}$ $(0.1 \mathrm{~mol} / \mathrm{L})$ and polymethacrylic acid (PMAA) $(10 \mathrm{~g} / \mathrm{L})$ were prepared firstly. In a typical experiment, $10 \mathrm{~mL}$ of $\mathrm{SrCl}_{2}$ solution $(0.1 \mathrm{~mol} / \mathrm{L}), 0.5 \mathrm{~mL}$ of PMAA solution $(10 \mathrm{~g} / \mathrm{L})$ and $29.5 \mathrm{~mL}$ of distilled water were mixed in a beaker under magnetic stirring for $5 \mathrm{~min}$. Then, $10 \mathrm{~mL}$ of $\mathrm{Na}_{2} \mathrm{WO}_{4}$ solution $(0.1 \mathrm{~mol} / \mathrm{L})$ was slowly added under vigorous stirring, giving final concentrations of $0.02 \mathrm{~mol} / \mathrm{L}$ for both $\mathrm{Sr}^{2+}$ and $\mathrm{WO}_{4}{ }^{2-}$ and $0.1 \mathrm{~g} / \mathrm{L}$ for PMAA. The starting $\mathrm{pH}$ value of the mixture was adjusted to 12 using $2 \mathrm{~mol} / \mathrm{L} \mathrm{NaOH}$ or $\mathrm{HCl}$ solution. After continuous vigorous stirring for $5 \mathrm{~min}$, the mixture was sealed and incubated at room temperature for $12 \mathrm{~h}$. The resulting white precipitate was washed with distilled water and ethanol, and dried in air. Tungsten oxide hydrate hollow microspheres were accomplished by soaking the as-prepared $\mathrm{SrWO}_{4}$ samples in a concentrated $\mathrm{HNO}_{3}$ solution $(8 \mathrm{~mol} / \mathrm{L})$ at room temperature for $24 \mathrm{~h}$, and then washing with distilled water and ethanol for three times, respectively. The washed precipitate was dried in a vacuum oven at $60{ }^{\circ} \mathrm{C}$ for $8 \mathrm{~h}$ and finally calcined at $300{ }^{\circ} \mathrm{C}$ for $2 \mathrm{~h}$ in air.

\subsection{Preparation of $\mathrm{WS}_{2}$ hollow sphere}

A gas-solid reaction was performed under inert gas (nitrogen) to prepare the $\mathrm{WS}_{2}$ samples. The prepared $\mathrm{WO}_{3}$ was employed as tungsten precursor and $\mathrm{CS}_{2}$ (ACS reagent $>99.9 \%$, Sigma-Aldrich) as a sulfur source. In detail, $1.0 \mathrm{~g}$ of the prepared $\mathrm{WO}_{3}$ hollow spheres was weighed and placed in a ceramic boat. The ceramic boat was positioned in a quartz tube furnace whose ends were equipped with high-temperature O-rings and stainless steel lids for gas introduction and exhaust. A gas purge step was performed to make sure that no oxygen was present inside the reactor. The quartz tube was then inserted into the clamp tubular furnace, and the temperature was raised to $550{ }^{\circ} \mathrm{C}$ at a heating rate of $5{ }^{\circ} \mathrm{C} \mathrm{min}^{-1}$, then the nitrogen gas with $\mathrm{CS}_{2}$ vapor was introduced into the quartz tube for the reaction to occur at different durations of $1 \mathrm{~h}, 2 \mathrm{~h}$ and $3 \mathrm{~h}$. After the reaction time was over, the powder was allowed to cool under the gas and then it was 
subjected to further characterization. The samples were labeled $\mathrm{WO}_{3}, \mathrm{WS}_{2}-1, \mathrm{WS}_{2}-2$ and $\mathrm{WS}_{2}-3$ to denote the sulfidation period of $0 \mathrm{~h}, 1 \mathrm{~h}, 2 \mathrm{~h}$, and $3 \mathrm{~h}$, respectively.

\subsection{Characterization}

Powder X-ray diffraction (XRD) investigations were conducted on an X-ray diffractometer (Rigaku, Japan) using $\mathrm{CuK} \alpha$ irradiation $(\lambda=0.15418 \mathrm{~nm})$ at a scan rate of $0.05 \%$. Transmission electron microscopy (TEM) and high-resolution transmission electron microscopy (HRTEM) analyses were conducted using a JEM-2100F electron microscope (JEOL, Japan).The element distribution mapping measurement was performed on an S4800 field emission scanning electron microscope (FE-SEM, Hitachi, Japan) equipped with an X-Max 50 energy-dispersive X-ray spectroscopy (EDS, Oxford Instruments, Britain) with an accelerating voltage of $10 \mathrm{kV}$. The Brunauer-Emmett-Teller (BET) specific surface area $\left(\mathrm{S}_{\mathrm{BET}}\right)$ of the samples was determined by nitrogen adsorption data in a Micromeritics ASAP 2020 nitrogen adsorption apparatus (USA). All the samples were degassed at $180{ }^{\circ} \mathrm{C}$ before the nitrogen adsorption measurements. A desorption isotherm was used to determine the pore size distribution by the BarretJoyner-Halender (BJH) method, using a cylindrical pore model [31]. The nitrogen adsorption volume at the relative pressure $\left(\mathrm{P} / \mathrm{P}_{0}\right)$ of 0.99 was used to calculate the pore volume and average pore size. X-ray photoelectron spectroscopy (XPS) measurements were done by using an ultrahigh vacuum VG ESCALAB 210 electron spectrometer equipped with a multichannel detector, using $\mathrm{MgK} \alpha(1253.6 \mathrm{eV})$ radiation (operated at $200 \mathrm{~W}$ ) of a twin anode in a constant analyzer energy mode with a pass energy of $30 \mathrm{eV}$. All the binding energies were referenced to the $\mathrm{C} 1 \mathrm{~s}$ peak at $284.8 \mathrm{eV}$ of the surface adventitious carbon. The optical absorption properties of the samples were obtained with a UV-Vis absorption spectrophotometer (UV-2600, Shimadzu, Japan). $\mathrm{BaSO}_{4}$ was used as a reflectance standard in the UV-Vis reflectance experiment.

\subsection{DFT computational details}

The energy calculations were based on DFT using the CASTEP code with the plane-wave pseudopotential method [32]. The exchange-correlation function based on generalized gradient approximation (GGA) with the Perdew-Burke-Ernzerhof (PBE) was used. The interaction between valence electrons and the ionic core was described by the ultrasoft pseudopotential $[33,34]$. The atomic coordinates and lattice parameters were relaxed by the cutoff of $460 \mathrm{eV}$ and Monkhorst-Pack grids of $9 \times 9 \times 2$ k-points. Other convergence tolerance parameters used for geometry optimization calculations were a total energy of $1 \times 10^{-5} \mathrm{eV}$ per atom, maximum force $0.03 \mathrm{eV}$ per $\AA$, a maximum stress of $0.05 \mathrm{GPa}$ and a maximum atomic displacement of $0.001 \AA$. The valence electron configurations of $W-5 s^{2} 5 p^{6} 5 d^{4} 6 s^{2}$ and $S-3 s^{2} 3 p^{4}$ were used for the bulk $\mathrm{WS}_{2}$ calculation, while the inner electrons were kept frozen as core states. Higher cutoff energy and denser k-point grids cannot obviously change the energy and the geometry structure of $\mathrm{WS}_{2}$. After finishing the geometry optimization, the band structures and density of state (DOS) of the bulk $\mathrm{WS}_{2}$ were calculated.

\section{Results and discussion}

\subsection{Morphology and phase microstruc- ture analysis}

The SEM images of both the synthesized pure $\mathrm{WO}_{3}$ and $\mathrm{WS}_{2}$ samples are shown in Fig. 1. Sulfidation process was used to convert the prepared $\mathrm{WO}_{3}$ into $\mathrm{WS}_{2}$. The morphology of the $\mathrm{WO}_{3}$ resembles a hollow in nature microsphere with the diameter of $2 \mu \mathrm{m}$ to $4 \mu \mathrm{m}$. It can be seen that after the sulfidation process at different durations, the $\mathrm{WO}_{3}$ precursor and the $\mathrm{WS}_{2}$ samples have similar morphologies, suggesting that $\mathrm{WS}_{2}$ preparation process (i.e. sulfidation) did not affect the morphology of the $\mathrm{WO}_{3}$ precursor. It was also evidenced by the low magnification TEM micrographic studies (Fig. 2a). From the HRTEM images presented in Fig. 2b and Fig. 2c, onion-like layers with crystal lattice fringes spacing of ca. $0.62 \mathrm{~nm}$, corresponding to the $\left(\begin{array}{lll}0 & 0\end{array}\right)$ plane of $2 \mathrm{H}-\mathrm{WS}_{2}$ have been 
revealed $[35,36]$. These images suggest that there is the dominance of layered arrays in the structure which is characteristic of $\mathrm{WS}_{2}$. EDX elemental mapping distribution was carried out to determine the presence of all the elements in the as-prepared $\mathrm{WS}_{2}$ sample. Fig. 3 shows the mapping images obtained where only $\mathrm{W}$ and $\mathrm{S}$ elements were detected. Besides, the quantitative analysis of elements based on the EDS result was performed and $\mathrm{W}: \mathrm{S}$ atomic ratio was calculated to be 1.1:2.3 which is close to the stoichiometric ratio of 1:2. Based on this study, it is clear that $\mathrm{WS}_{2}$ has been synthesized.

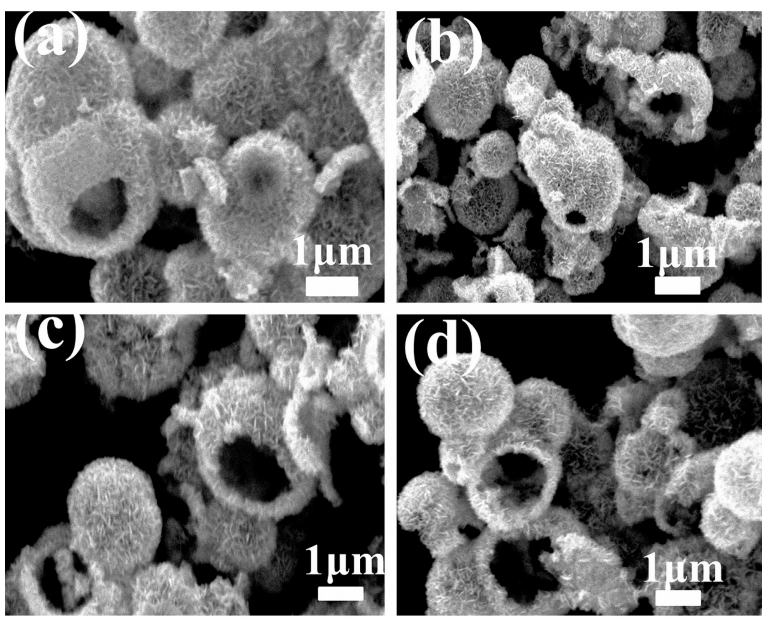

Fig. 1. SEM images for pure $\mathrm{WO}_{3}(\mathrm{a}), \mathrm{WS}_{2}-1$ (b), $\mathrm{WS}_{2}-2$ (c), and $\mathrm{WS}_{2}-3$ (d).

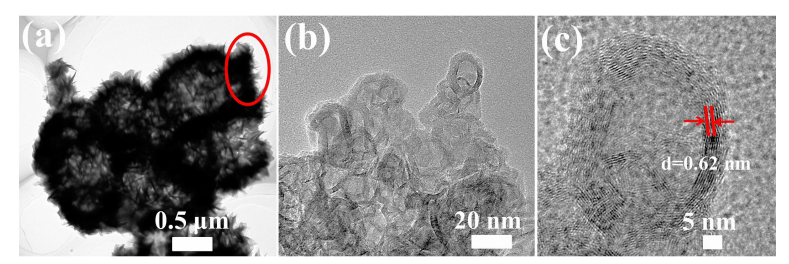

Fig. 2. (a) TEM image; (b) and (c) HRTEM images of $\mathrm{WS}_{2}-3$ sample.

$\mathrm{XRD}$ analysis was carried out to show the phase structures of the pure $\mathrm{WO}_{3}$ precursor and the asprepared $\mathrm{WS}_{2}$ samples. Fig. 4 shows the XRD pattern of the pure $\mathrm{WO}_{3}$ before and after the sulfidation period (i.e. for $\mathrm{WS}_{2}$ samples). The diffraction peaks of the $\mathrm{WO}_{3}$ XRD pattern can be indexed to the pure monoclinic phase of $\mathrm{WO}_{3}$ (JCPDS Card

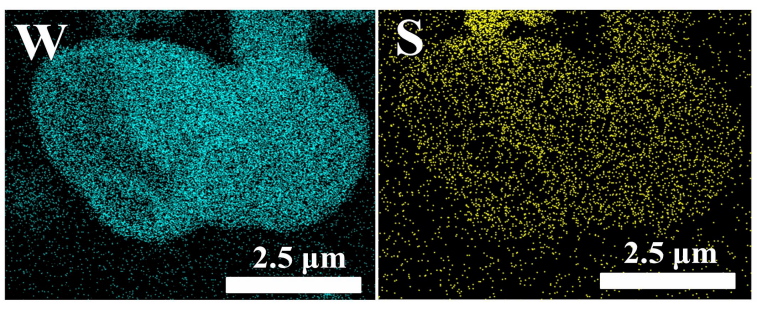

Fig. 3. EDX elemental mapping for $\mathrm{WS}_{2}-3$ sample showing $\mathrm{W}$ and $\mathrm{S}$ elements.

No. $72-1465, a=7.3 \AA, b=7.53 \AA, c=7.68 \AA$ ). The XRD patterns of the as-prepared $\mathrm{WS}_{2}$ samples differ from that of the $\mathrm{WO}_{3}$ precursor suggesting phase change during the sulfidation process. It can be seen that after $1 \mathrm{~h}$ sulfidation process, all $\mathrm{WO}_{3}$ peaks completely disappeared resulting in the appearance of peaks corresponding to $\mathrm{WS}_{2}$, which confirms that the $\mathrm{S}$ atom from the $\mathrm{CS}_{2}$ gas has started replacing the $\mathrm{O}$ atoms in the $\mathrm{WO}_{3}$, resulting in the partial formation of $\mathrm{WS}_{2}$. Notably, among them a diffraction peak at $13.9^{\circ}$ corresponding to (lll $\left.\begin{array}{ll}0 & 0\end{array}\right)$ plane has appeared which is an indication of the $\mathrm{WS}_{2}$ layer or coating formation on the precursor. Further increase in the sulfidation period resulted in higher $\mathrm{WS}_{2}$ peak intensities and showed completed structure after $3 \mathrm{~h}$ sulfidation period. It can be observed from Fig. $4 \mathrm{~b}$ that the XRD pattern of as-prepared $\mathrm{WS}_{2}$ samples matches the pure crystal phase of hexagonal $\mathrm{WS}_{2}$ structure which is indexed to PDF Card No. 35-0651. The intense peak at $13.9^{\circ}$ corresponding to $\left(\begin{array}{lll}0 & 0 & 2\end{array}\right)$ plane indicates the formation of well-stacked layered $\mathrm{WS}_{2}$ structure. This result is in agreement with other previous studies $[11,20,37]$.

\subsection{BET surface area and pore size distri- bution}

The nitrogen adsorption-desorption isotherms of the pure $\mathrm{WO}_{3}$ and the $\mathrm{WS}_{2}$ as-prepared samples are shown in Fig. 5. Both samples exhibit isotherms of type IV BDDT (Brunauer-DemingDeming-Teller) classification suggesting bimodal pore size distribution in the mesoporous and macroporous regions. The hysteresis loops in relatively lower pressure range $\left(0.5<\mathrm{P} / \mathrm{P}_{0}<0.8\right)$ are associated with finer intra-aggregated pores 

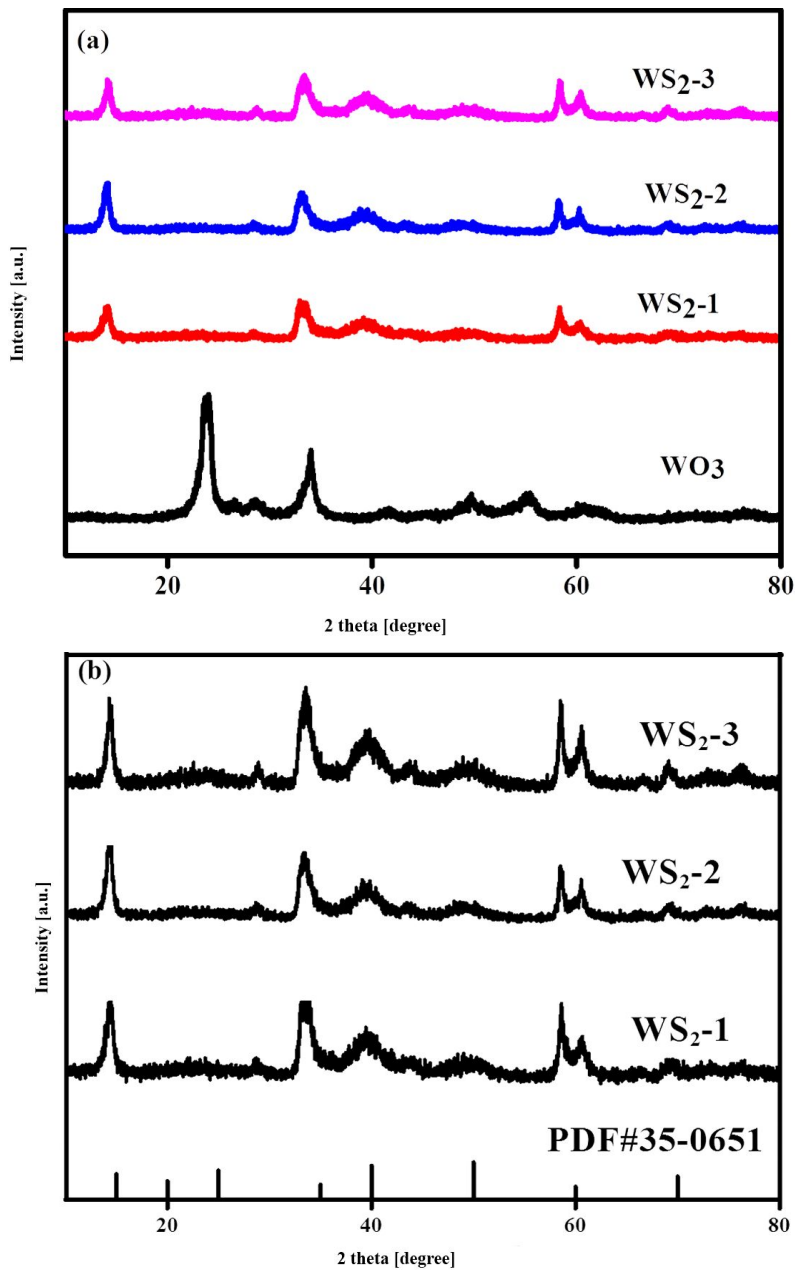

Fig. 4. (a) XRD patterns of pure $\mathrm{WO}_{3}$ and $\mathrm{WS}_{2}$ at different sulfidation times; (b) comparison of XRD patterns of as-prepared $\mathrm{WS}_{2}$ samples and PDF Card No. 35-0651.

in the agglomerated particles while in the higher relative pressure range $\left(0.8<\mathrm{P} / \mathrm{P}_{0}<1\right)$, it is related with larger inter-aggregated pores between the aggregated particles [30]. The presence of the bimodal pore in the as-prepared samples was further confirmed by the pore-size distribution curves shown as an inset in Fig. 5. The BJH (Barrett-Joyner-Halenda) method was employed to determine the desorption branch of the nitrogen isotherm. The pore size distribution shows a broad range of pore size diameters from $2 \mathrm{~nm}$ to $130 \mathrm{~nm}$. The $\mathrm{WS}_{2}$ as-prepared sample has small mesopores (peak pores at $2.5 \mathrm{~nm}$ and $3.6 \mathrm{~nm}$ ) and macropores (peak pore at $45 \mathrm{~nm}$ ), while the $\mathrm{WO}_{3}$ shows the peak pore of large mesopores at ca. $11 \mathrm{~nm}$ and macropores at $25 \mathrm{~nm}$. Table 1 illustrates the summary of physical properties of the as-prepared samples. It can be observed that the $\mathrm{WS}_{2}$ has a larger surface area, pore volume, and pore size compared to the $\mathrm{WO}_{3}$ precursor. The increase in these properties could be ascribed to the formation of $\mathrm{WS}_{2}$ layers on the surface of the precursor.

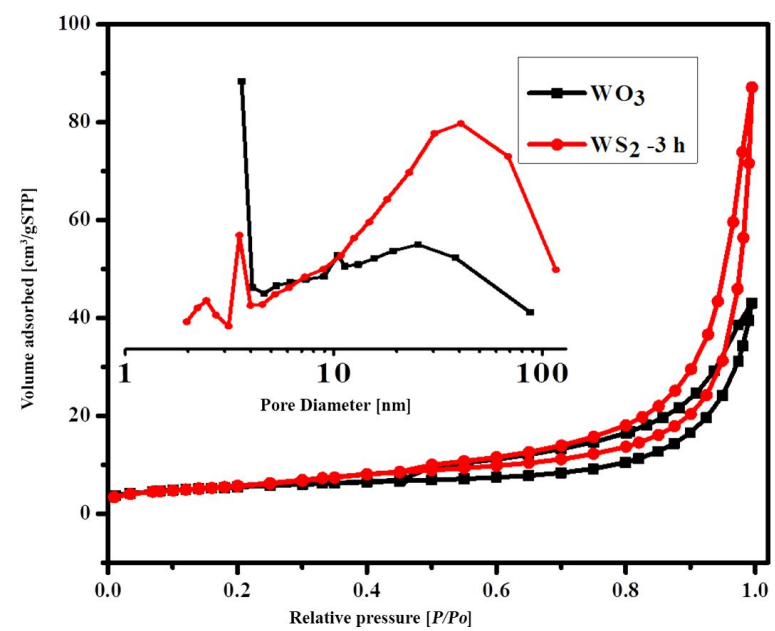

Fig. 5. Nitrogen adsorption isotherms of $\mathrm{WO}_{3}$ and asprepared $\mathrm{WS}_{2}-3$. The inset shows the pore size distribution curves.

\subsection{XPS analysis}

To further determine the chemical composition and the oxidation states of the elements in the asprepared $\mathrm{WS}_{2}$ samples, XPS analysis was carried out. The survey spectrum shows the presence of $\mathrm{O}$, $\mathrm{C}, \mathrm{S}$, and $\mathrm{W}$ in the $\mathrm{WS}_{2}$ prepared samples (Fig. 6). It can be seen from the spectrum that $\mathrm{W}$ and $\mathrm{S}$ elements have sharp peaks at $33.1 \mathrm{eV}$ and $161.2 \mathrm{eV}$ binding energy, respectively, with small peaks for $\mathrm{C}$ and $\mathrm{O}$. The carbon peak ( $\mathrm{C} 1 \mathrm{~s} 285 \mathrm{eV}$ ) is attributed to surface adventitious carbon which comes from the sample and the XPS instrument itself. The oxygen peak $(\mathrm{O} 1 \mathrm{~s} 532 \mathrm{eV})$ could come from adsorbed water molecules on the surface of the sample.

Fig. 7a illustrates the high-resolution spectrum of $\mathrm{W} 4 \mathrm{f}$ showing two core peaks with binding energies at $32.2 \mathrm{eV}$ and $34.2 \mathrm{eV}$ for $4 \mathrm{f}_{7 / 2}$ and $4 \mathrm{f}_{5 / 2}$, respectively. These peaks can be ascribed to the $\mathrm{W}^{4+}$ 
Table 1 . Summary of the physical properties of the $\mathrm{WO}_{3}$ and $\mathrm{WS}_{2}-3 \mathrm{~h}$ samples.

\begin{tabular}{cccc}
\hline Sample & $\mathrm{S}_{\text {BET }}\left[\mathrm{m}^{2} / \mathrm{g}\right]$ & Pore volume $\left[\mathrm{cm}^{3} / \mathrm{g}\right]$ & Average pore size $[\mathrm{nm}]$ \\
\hline \hline $\mathrm{WO}_{3}$ & 19.3 & 0.05 & 10.0 \\
$\mathrm{WS}_{2}-3$ & 20.3 & 0.07 & 14.0 \\
\hline
\end{tabular}

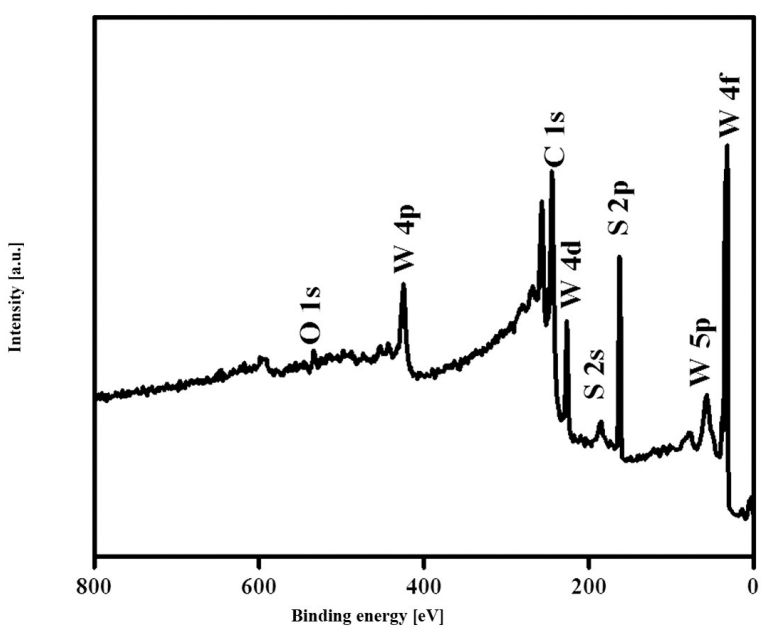

Fig. 6. Survey spectrum of the as-prepared $\mathrm{WS}_{2}$ sulfided for $3 \mathrm{~h}$.

species in the as-prepared samples [36, 38]. The high-resolution spectrum of the $S 2 p$ core region has two characteristic peaks at binding energies of $162.0 \mathrm{eV}$ and $163.2 \mathrm{eV}$ for $2 \mathrm{p}_{3 / 2}$ and $2 \mathrm{p}_{1 / 2}$, respectively. These peaks correspond to $\mathrm{S}^{2-}$ species in the samples [25]. Combining this result with the $\mathrm{W} 4 \mathrm{f}$ spectrum, confirms the formation of $\mathrm{WS}_{2}$.

\subsection{UV-Vis spectra and optical properties}

The light harvesting or optical properties of the as-prepared $\mathrm{WS}_{2}$ samples was characterized by UV-Vis absorption spectroscopy. The UV-Vis spectra of the $\mathrm{WO}_{3}$ precursor and as-prepared $\mathrm{WS}_{2}$ samples are shown in Fig. 8a. It can be seen that the $\mathrm{WO}_{3}$ has an absorption edge at $\sim 468 \mathrm{~nm}$ which corresponds to the band gap of $2.65 \mathrm{eV}$ and agrees with previous studies [30, 39]. The as-prepared $\mathrm{WS}_{2}$ samples display an extended absorption to $820 \mathrm{~nm}$ corresponding to the bandgap of $\sim 1.5 \mathrm{eV}$ as shown in Fig. 8b. According to the literature, bulk $\mathrm{WS}_{2}$ has the absorption edge at $\sim 920 \mathrm{~nm}$ (1.35 eV bandgap), so the bandgap of $\sim 1.5 \mathrm{eV}$ is an indication of large blue shift for the as-prepared
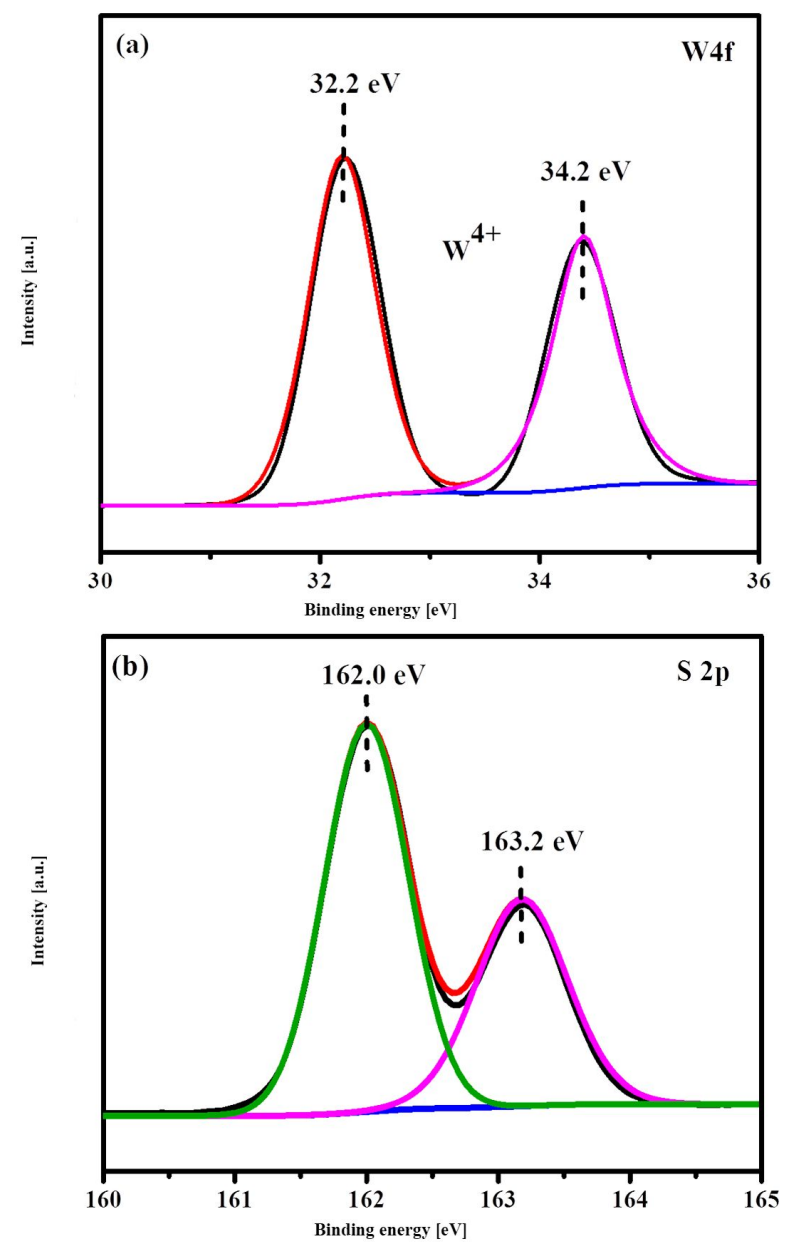

Fig. 7. High-resolution XPS spectra; (a) W 4f and (b) $\mathrm{S} 2 \mathrm{p}$ of as-prepared $\mathrm{WS}_{2}$ sample sulfided for $3 \mathrm{~h}$.

$\mathrm{WS}_{2}$ samples due to strong quantum confinement effect in the samples. This quantum confinement effect leads to an increase in the band gap and a change in redox potential $[10,25]$. The spectra of the as-prepared $\mathrm{WS}_{2}$ samples also show a characteristic A-B excitonic peak positions at the wavelengths $616 \mathrm{~nm}$ and $513 \mathrm{~nm}$ which correspond to $2.0 \mathrm{eV}$ and $2.4 \mathrm{eV}$ band gaps, respectively. The excitonic peaks are related to direct strong valence band spin-orbit splitting at the Brillouin zone 
$\mathrm{K}$ point $[11,25,40]$ and is present only in the bulk $\mathrm{WS}_{2}$, which further confirms the formation of bulk $\mathrm{WS}_{2}$.
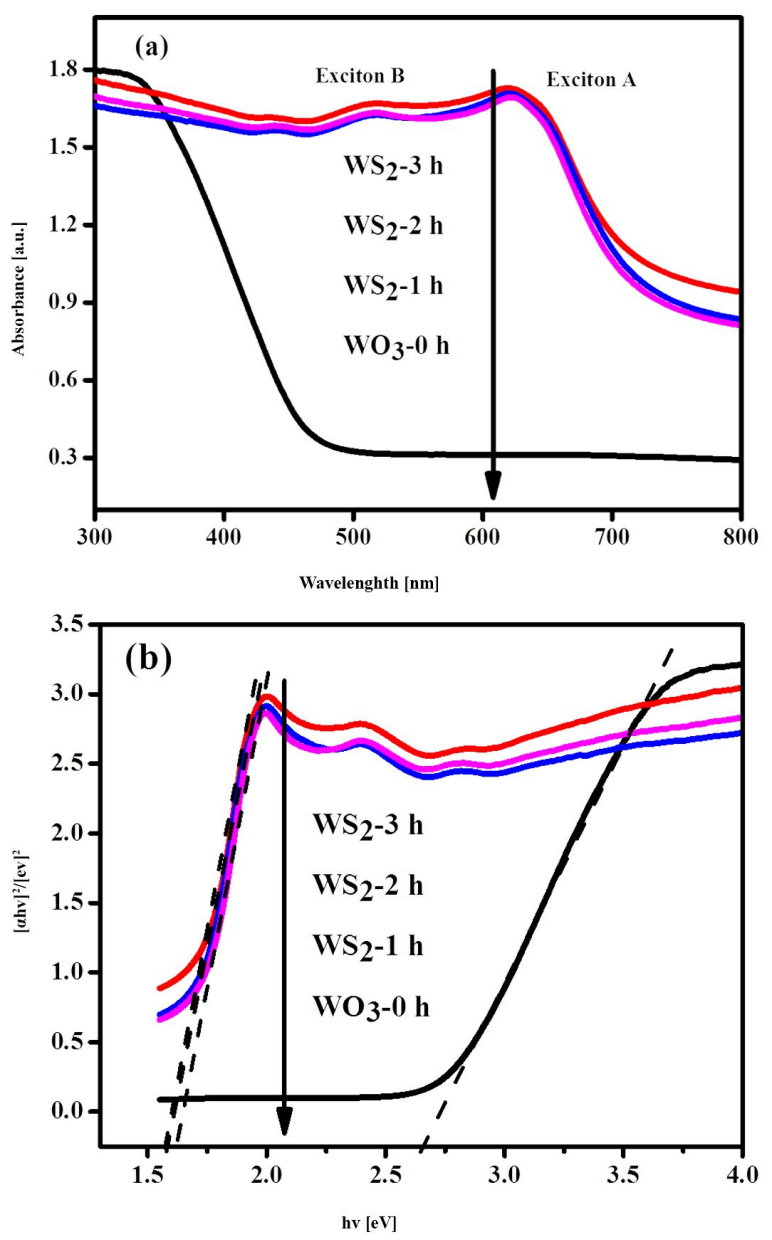

Fig. 8. (a) UV-Vis diffuse reflection spectra; (b) Kubelka-Munk function for band gap energies of the as-prepared samples.

\subsection{Electronic structure}

Fig. 9 shows the conventional unit cell of bulk $\mathrm{WS}_{2}$ respectively, which have $2 \mathrm{H}$ polytype crystalline system with hexagonal symmetry and space group $\mathrm{P} 63 / \mathrm{mmc}\left(\mathrm{D}_{6 \mathrm{~h}}^{4}\right)$. The experimental lattice parameters used in this study were $(\mathrm{a}=\mathrm{b}=3.153 \AA$, $\mathrm{c}=12.323 \AA$, and $\left.\alpha=\beta=90^{\circ}, \gamma=120^{\circ}\right)[41,42]$. DFT was used to perform geometry optimization for the lattice parameters before calculating the electronic structures. The obtained optimized lattice constants are $\mathrm{a}=\mathrm{b}=3.184 \AA, \mathrm{c}=14.297 \AA$, and $\alpha=\beta=90^{\circ}$, which shows slight overestimation relative to the experimental results, which is due to the shortcoming of exchange-correlation function of GGA. The percentage deviations between the calculated and experimental values are within $2.0 \%$, which is an indication of sufficient accuracy in the pseudopotential used for the calculations.

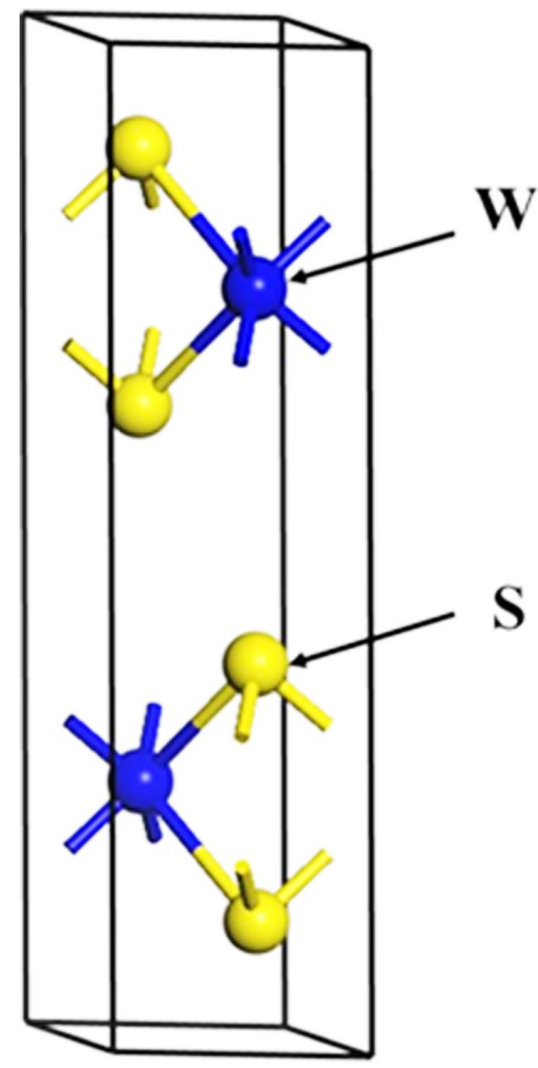

Fig. 9. A schematic conventional unit cell of hexagonal phase $\mathrm{WS}_{2}$.

To clarify the underlying electronic properties of $\mathrm{WS}_{2}$, the band structures of $\mathrm{WS}_{2}$ along the high symmetry directions were calculated and shown in Fig. 10. The dashed line shows the Fermi level which was set at zero. It can be seen that the valence bands of $\mathrm{WS}_{2}$ can be divided into four band regions (Fig. 10a). The conduction band minimum $(\mathrm{CBM})$ is located at $\mathrm{Z}$ point, while the valence band maximum (VBM) is located at $G$ point, which confirms that the $\mathrm{WS}_{2}$ is an indirect band gap semiconductor. The difference between the bands 
leads to a conclusion that there is an energy gap between the conduction and valence band at the Fermi level which is determined to be about $1.56 \mathrm{eV}$ (Fig. 10b). It is in a good agreement with other calculated results $[43,44]$. The band gap obtained for the as-prepared $\mathrm{WS}_{2}$ samples is $\sim 1.5 \mathrm{eV}$ (Fig. 8), further indicating the reliability of the DFT calculation.
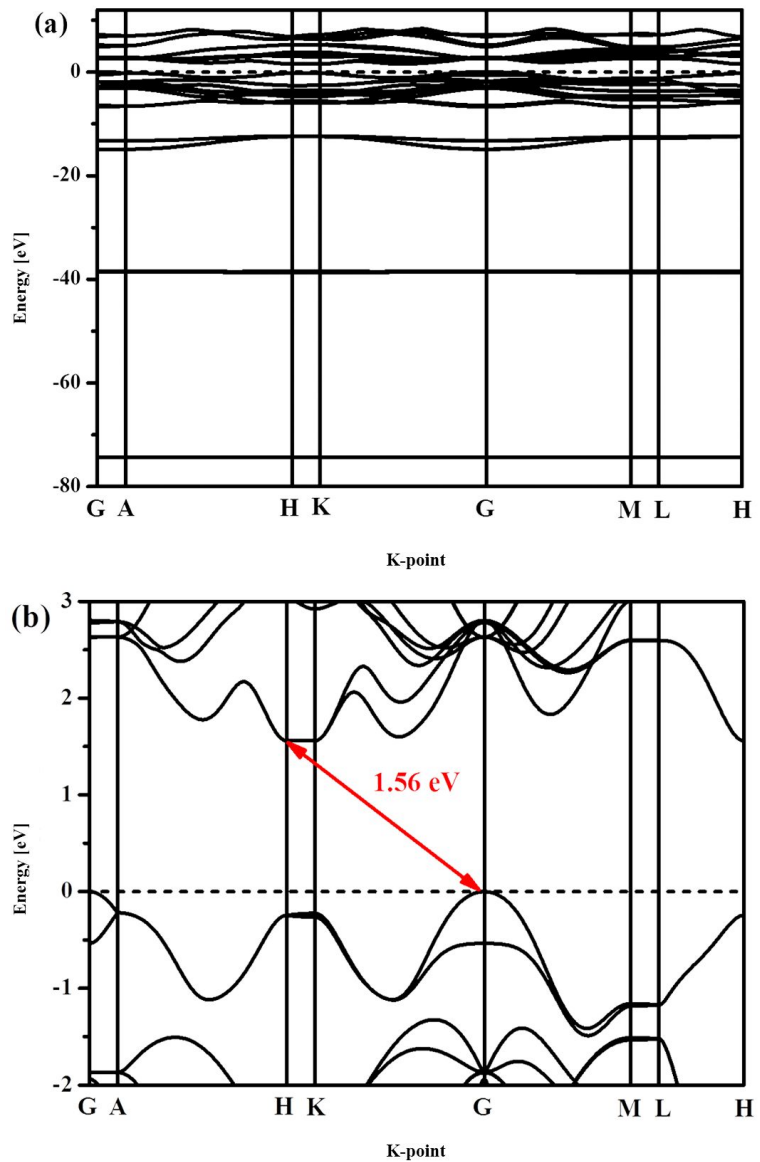

Fig. 10. (a) The band structures of $\mathrm{WS}_{2}$ and (b) a magnified band structure around the Fermi level.

To further understanding the composition and nature of the band structures, the TDOS of $\mathrm{WS}_{2}$ and PDOS of $\mathrm{W}$ and $\mathrm{S}$ have been calculated and shown in Fig. 11. The valance bands at $-74.0 \mathrm{eV}$ and $-38.0 \mathrm{eV}$ correspond to $\mathrm{W} 6 \mathrm{~s}$ and $\mathrm{W} 5 \mathrm{p}$ states, respectively. The valance bands between $-15 \mathrm{eV}$ and $-11 \mathrm{eV}$ are mainly contributed by $\mathrm{S} 3 \mathrm{~s}$ states and a few W $6 \mathrm{~s}, 5 \mathrm{~d}$ states. The upper valence bands between $-7.0 \mathrm{eV}$ and $0 \mathrm{eV}$ are mainly contributed by $\mathrm{S} 3 \mathrm{p}$ states and a few $\mathrm{W} 5 \mathrm{~d}$ states. However, the conduction band is mainly composed by W $5 \mathrm{~d}$ states, mixed with a few S 3p states. This suggests the existence of strong $\mathrm{p}-\mathrm{d}$ hybridization between $\mathrm{S}$ atoms and $\mathrm{W}$ states in the valence and conduction bands. These observations agree well with other previous reports [45].

\section{Conclusions}

$\mathrm{WS}_{2}$ was successfully prepared via a gas-solid reaction where $\mathrm{WO}_{3}$ precursor was sulfided with $\mathrm{CS}_{2}$ at $550{ }^{\circ} \mathrm{C}$ at different durations under $\mathrm{N}_{2}$ inert gas atmosphere. The reaction occurred by substitution of $\mathrm{O}$ by $\mathrm{S}$ during the sulfidation process. Characterization of the as-prepared $\mathrm{WS}_{2}$ samples confirmed the formation of $\mathrm{WS}_{2}$ in the appropriate stoichiometric ratio. The calculated results indicate
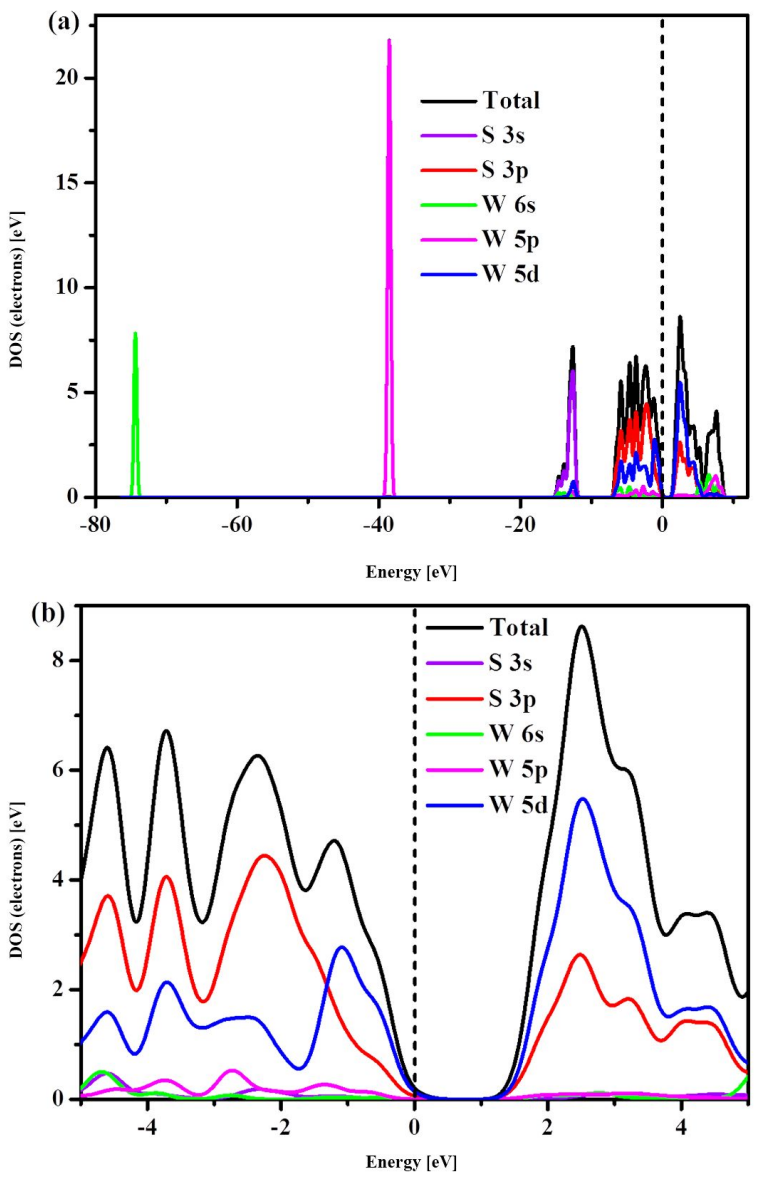

Fig. 11. (a) The DOS of $\mathrm{WS}_{2}$ and (b) the magnified DOS around the Fermi level. 
that $\mathrm{WS}_{2}$ has an indirect band gap of ca. $1.56 \mathrm{eV}$, which is very close to the experimental band gap of ca. $1.50 \mathrm{eV}$. Combining the experimental and DFT results suggests that the novel method used in the synthesis of $\mathrm{WS}_{2}$ has a potential application for large scale production. The obtained $\mathrm{WS}_{2}$ are of high quality, presenting appropriate properties for applications in photocatalysis, catalysis, photovoltaics, optoelectronic devices and photosensor devices.

\section{Acknowledgements}

The authors would like to acknowledge the financial support from the Ghana Government Book and Research Allowance for tertiary institutions. We also acknowledge contributions from members of the Mechanical Engineering Department of the Ho Technical University, Ghana, and the State Key Laboratory of Advanced Technology for Material Synthesis and Processing, Wuhan University of Technology, Wuhan 430070, P.R. China, for supporting the research in diverse ways.

\section{References}

[1] Chen S.Y., Zheng C., Fuhrer M.S., Yan J., Nano. Lett., 15 (2015), 2526.

[2] Wang Y., Cong C., Yang W., Shang J., Peimyoo N., Chen Y., Kang J., Wang J., HUANG W., YU T., Nano Res., (2015), 1.

[3] Wang Q.H., Kalantar-Zadeh K., Kis A., ColeMAN J.N., STRANO M.S., Nat. Nanotechnol., 7 (2012), 699.

[4] Zhan Y., LiU Z., Najmaei S., Ajayan P.M., Lou J., Small, 8 (2012), 966.

[5] Zeng H., Dai J., Yao W., Xiao D., Cui X., Nat. Nanotechnol., 7 (2012), 490.

[6] Ghoreishi S., Meshiat S., Dadkhah A., Mater. Res. Bull., 45 (2010), 584.

[7] Chou S.S., Huang Y.K., Kim J., Kaehr B., Foley B.M., LU P., DYKSTRA C., Hopkins P.E., BRINKER C.J, Huang J., J. Am. Chem. Soc., 137 (2015), 1742.

[8] Lukowski M.A., Daniel A.S., English C.R., Meng F., Forticaux A., Hamers R. J., Jin S., Energ. Environ. Sci., 7 (2014), 2608.

[9] PARK J., LeE W., Choi T., Hwang S. H., Myoung J.M, Jung J. H, KIM S. H, KIM H., Nanoscale, 7 (2015), 1308.

[10] Elías A. L., Perea-López N., CastroBeltrán A., Berkdemir A., LV R., Feng S., LONG A. D., HAYASHI T., KIM Y. A., ENDO M., ACS Nano, 7 (2013), 5235.

[11] Notley S.M., J. Colloid Interf. Sci., 396 (2013), 160.

[12] Chen D., Tang K., Shen G., Sheng J., Fang Z., LiU X., Zheng H., QIan Y., Mater. Chem. Phys., 82 (2003), 206.
[13] Ellmer K., Phys. Status Solidi B, 245 (2008), 1745.

[14] Hou X., Shan C., Choy K.L., Surf. Coat. Technol., 202 (2008), 2287.

[15] Margolin A., Deepak F., Popovitz-Biro R., BAR-SAdAN M., Feldman Y., TEnNE R., Nanotechnology, 19 (2008), 095601.

[16] WU J., Fu X., Mater. Lett., 61 (2007), 4332.

[17] Wiesel I., Arbel H., Albu-Yaron A., PopovitzBiro R., Gordon J.M., Feuermann D., TEnne R., Nano Res., 2 (2009), 416.

[18] Wen Y., Zhang H., Zhang S., Nanoscale, 6 (2014), 13090.

[19] Choi S.H., Boo S.J., Lee J. H., Kang Y.C., Sci. Rep.-UK, 4 (5755) (2014), 4.

[20] James D., Zubkov T., J. Photoch. Photobio. A, 262 (2013), 45.

[21] Cao S., Liu T., Hussain S., Zeng W., Pan F., PENG X., J. Mater. Sci.-Mater. El., 26 (2015), 809.

[22] Thangaraja A., Shinde S.M., Kalita G., TaneMURA M., Mater. Lett., 156 (2015), 156.

[23] YAng J., Voiry D., Ahn S.J., Kang D., Kim A.Y., ChHowalla M., Shin H.S., Angew. Chem. Int. Edit., 52 (2013), 13751.

[24] Chhowalla M., Shin H.S., Eda G., Li L.J., LOH K.P., Zhang H., Nat. Chem., 5 (2013), 263.

[25] Morrish R., HaAk T., Wolden C.A., Chem. Mater., 26 (2014), 3986.

[26] Tehrani M., Luhrs C., Al-Haik M., Trevino J., ZEA H., Nanotechnology, 22 (2011), 285714.

[27] Cao S., Liu T., Hussain S., Zeng W., Peng X., PAN F., Mater. Lett., 129 (2014), 205.

[28] Sun S., Zou Z., Min G., Mater. Chem. Phys., 114 (2009), 884.

[29] Zhao X., Cheung T.L., Zhang X., NG D.H., YU J., J. Am. Ceram. Soc., 89 (2006), 2960.

[30] Yu J., Qi L., Cheng B., Zhao X., J. Hazard. Mater., 160 (2008), 621.

[31] Sing K.S., Pure Appl. Chem., 57 (1985), 603.

[32] Segall M., Lindan P.J., Probert M.A., Pickard C., Hasnip P., Clark S., Payne M., J. Phys. Condens. Mat., 14 (2002), 2717.

[33] Perdew J. P., Burke K., Ernzerhof M., Phys. Rev. Lett., 77 (1996), 3865.

[34] Perdew J. P., Wang Y., Phys. Rev. B, 45 (1992), 13244.

[35] Hou Y., Laursen A.B., Zhang J., Zhang G., ZhU Y., WANG X., DAHL S., ChORKENDORFF I., Angew. Chem., Int. Edit., 52 (2013), 3621.

[36] Yang L., Zhou H., FAN T., Zhang D., PCCP, 16 (2014), 6810.

[37] Wu Z., WAng D., Zan X., Sun A., Mater. Lett., 64 (2010), 856.

[38] Zong X., Han J. , Ma G., Yan H., Wu G., Li C., J. Phys. Chem. C, 115 (2011), 12202.

[39] Jin J., Yu J., Guo D., Cui C., Ho W., Small, 11 (2015), 5262. 
[40] Rodriguez Gutierrez H., Perea-López N., Elías A. L., Berkdemir A., WANG B., LV R., López-Urías F., Crespi V., Terrones H., TerRONES M., J. APS, March Meeting Abstracts, (2013), 5007.

[41] Wilson J., Yoffe A., Adv. Phys., 18 (1969), 193.

[42] Kuc A., Zibouche N., Heine T., Phys. Rev. B, 83 (2011), 245213.

[43] Sayan R., Peter B., Sol. Energ. Mat. Sol. C., 174 (2018), 370.
[44] Forti S., Rossi A., BÜCH H., Cavallucci T., BIsio F., Sala A., Menteş T. O., Locatelli A., Magnozzi M., Canepa M., Müller K., Link S., Starke U., Tozzinib V., Colett C., Nanoscale, 9 (2017), 16412

[45] Kumar A., Ahluwalia P., Eur. Phys. J. B, 85 (2012), 1.

Received 2017-05-17 Accepted 2018-03-15 